\title{
Video Article \\ Characterization of Tumor Cells Using a Medical Wire for Capturing Circulating Tumor Cells: A 3D Approach Based on Immunofluorescence and DNA FISH
}

\author{
Giulia Gallerani ${ }^{1}$, Claudia Cocchi ${ }^{2}$, Martine Bocchini ${ }^{3}$, Filippo Piccinini ${ }^{1}$, Francesco Fabbri ${ }^{1}$ \\ ${ }^{1}$ Biosciences Laboratory, Istituto Scientifico Romagnolo per lo Studio e la Cura dei Tumori (IRST) IRCCS \\ ${ }^{2}$ Associazione Annastaccatolisa Onlus \\ ${ }^{3}$ Nuclear Medicine Unit, Istituto Scientifico Romagnolo per lo Studio e la Cura dei Tumori (IRST) IRCCS
}

Correspondence to: Giulia Gallerani at giulia.gallerani@irst.emr.it

URL: https://www.jove.com/video/56936

DOI: doi:10.3791/56936

Keywords: Cancer Biology, Issue 130, Oncology, circulating tumor cells, microscopy, image analysis, immunofluorescence, DNA FISH, 3D analysis, functionalized medical wire, ALK gene

Date Published: 12/21/2017

Citation: Gallerani, G., Cocchi, C., Bocchini, M., Piccinini, F., Fabbri, F. Characterization of Tumor Cells Using a Medical Wire for Capturing Circulating Tumor Cells: A 3D Approach Based on Immunofluorescence and DNA FISH. J. Vis. Exp. (130), e56936, doi:10.3791/56936 (2017).

\section{Abstract}

Circulating tumor cells (CTCs) are associated with poor survival in metastatic cancer. Their identification, phenotyping, and genotyping could lead to a better understanding of tumor heterogeneity and thus facilitate the selection of patients for personalized treatment. However, this is hampered because of the rarity of CTCs. We present an innovative approach for sampling a high volume of the patient blood and obtaining information about presence, phenotype, and gene translocation of CTCs. The method combines immunofluorescence staining and DNA fluorescent-in-situ-hybridization (DNA FISH) and is based on a functionalized medical wire. This wire is an innovative device that permits the in vivo isolation of CTCs from a large volume of peripheral blood. The blood volume screened by a 30-min administration of the wire is approximately 1.5-3 L. To demonstrate the feasibility of this approach, epithelial cell adhesion molecule (EpCAM) expression and the chromosomal translocation of the ALK gene were determined in non-small-cell lung cancer (NSCLC) cell lines captured by the functionalized wire and stained with an immuno-DNA FISH approach. Our main challenge was to perform the assay on a 3D structure, the functionalized wire, and to determine immuno-phenotype and FISH signals on this support using a conventional fluorescence microscope. The results obtained indicate that catching CTCs and analyzing their phenotype and chromosomal rearrangement could potentially represent a new companion diagnostic approach and provide an innovative strategy for improving personalized cancer treatments.

\section{Video Link}

The video component of this article can be found at https://www.jove.com/video/56936/

\section{Introduction}

CTCs represent a key step of cancer cell dissemination ${ }^{1}$. Their presence in the peripheral blood of patients is associated with (metastatic) relapse and disease progression ${ }^{2,3}$. CTC isolation and characterization from the blood of cancer patients is a type of non-invasive liquid biopsy. In recent years, it has become increasingly evident that monitoring the progression and response of tumors to different treatments using this kind of analysis provides important clinical information ${ }^{4,5}$. Liquid biopsy is even more useful when surgery is not feasible or when primary tumor tissue is not available, i.e., for non-biopsiable lesions. Hence, this approach is promising in specific cancer settings such as metastatic NSCLC, where the presence of CTCs has been shown to have a negative prognostic role ${ }^{6}$. NSCLC is a tumor that benefits especially from targeted therapeutic approaches ${ }^{7,8,9}$ designed to act on specific molecules (molecular targets) known to be involved in the growth, progression, and spread of the disease. Hence, the detection of specific targets during disease progression is needed. CTC investigation is an extremely interesting diagnostic approach to detect and monitor drug targets without the need for primary or metastatic tissues. For example, the detection of ALK gene translocations in NSCLC cells is associated with sensitivity to crizotinib, a specific targeted therapy ${ }^{10}$. However, at present, the detection of ALK translocations is executed only on fine-needle aspirates or small biopsies; as a result, without a tumor tissue ALK analysis is not possible. CTCs are a potential alternative to tumor tissue-based investigations and represent a highly promising companion diagnostic approach.

Despite their potential importance, CTCs are still a subject of great debate among research, mainly because of their rarity $(1-10 \mathrm{cells} / \mathrm{mL}$ of peripheral blood ${ }^{11}$ ). Current liquid biopsy methods use a limited amount of blood (i.e., 1-30 mL $)^{12,13}$, but this creates a situation of suboptimal sensitivity for the detection of CTCs. Hence, research is warranted to finding approaches and developing devices to perform CTC-targeted liquid biopsies on a larger volume of peripheral blood.

An alternative device, a functionalized medical wire (see Table of Materials), has been developed to overcome blood sampling limitations and obtain a more representative analysis of CTCs. This functionalized wire is a CE-approved medical device that captures CTCs directly from the bloodstream of cancer patients ${ }^{1}$. It is composed of a 16-cm-long stainless steel wire (Figure 1a) with a 2-cm-long functionalized tip coated with a $0.2-\mu \mathrm{m}$-thick layer of gold. The layer is in turn covered by a 1 to $5 \mu \mathrm{m}$-thick polycarboxylate hydrogel stratum covalently coupled with 
antibodies directed against the EpCAM, one of the most widely expressed antigens on the surface of CTCs ${ }^{14}$. The functionalized tip of the wire is introduced into a vein of the arm of the patient and remains in position for at least $30 \mathrm{~min}$. This approach allows isolation of CTCs in vivo, directly in peripheral blood, and to screen about $1.5-3.0 \mathrm{~L}$ of blood (approximately 300 -fold more than the volume used for alternative approaches) ${ }^{1}$.

Pantel et al. demonstrated the efficacy of this approach in isolating CTCs directly into the arm veins of lung cancer patients ${ }^{15}$. They performed wire immunofluorescence staining to identify CTCs using conventional antibodies directed against EpCAM and pan-cytokeratin, and CD45 for leucocyte detection. The wire was examined under an optical fluorescence microscope ${ }^{15}$. The authors demonstrated that the device was able to isolate CTCs, but they did not investigate any therapy-related targets, such as ALK translocations.

The presented method aims to identify putative CTCs in NSCLC cell lines on the basis of phenotypical parameters, e.g., EpCAM positivity and the presence of molecular biomarkers, for instance the ALK status (Figure 1b). This 3-day-long procedure combines a functionalized wire and immunofluorescence staining with DNA fluorescence-in-situ-hybridization (DNA FISH), named Immuno-DNA-FISH. Given that CTCs are rare entities, the advantage of this protocol is that CTCs can be characterized on the same wire in terms of both immunophenotypic features and DNA rearrangements.

\section{Immuno-DNA FISH on a 2D Coverslip}

\section{Coverslip preparation and adherent cell seeding}

NOTE: Perform all the following steps under a laminar-flow hood in sterile conditions.

1. Immerse the coverslip into $100 \%$ ethanol to disinfect them.

NOTE: We use $12 \mathrm{~mm} \times 12 \mathrm{~mm}$ silicone-supported squared coverslips (all reagents are listed in the Table of Materials).

2. Place the coverslips in a Petri dish (100 mm diameter). Dry using forced air flow for $5 \mathrm{~min}$.

3. Wash the Petri dish with $15 \mathrm{~mL}$ sterile $1 \times$ Dulbecco's phosphate buffered saline (PBS).

4. Wash the Petri dish with $10 \mathrm{~mL}$ of complete medium (see Table 1).

5. Seed adherent cells (about $1,650,000$ cells in $10 \mathrm{~mL}$ of medium, counted by FACS analysis) by gently dropping the cell suspension onto the Petri dish to obtain uniform cell plating (about 30,000 cells $/ \mathrm{cm}^{2}$ ).

Note: For $\sim 70 \%$ confluence, adherent cells should be cultured on coverslips for at least $48 \mathrm{~h}$.

\section{Fixation and permeabilization}

CAUTION: Acetone is a flammable and irritating volatile substance. Use only acetone-resistant plastics or glass containers (no PVC or PVDF).

NOTE: Perform these steps under a chemical fume hood.

1. Remove the culture medium using a disposable aspirating pipet.

2. Wash the Petri dish with $1 \times$ PBS.

3. Using tweezers, wash the coverslips by dipping them into a glass beaker containing $5 \mathrm{~mL}$ of $1 \times$ PBS.

4. Dry the coverslips on blotting paper.

5. Fix the cells on the coverslip by immersing it into a $100 \%$ acetone solution for $10 \mathrm{~min}$ at room temperature (RT).

6. Remove the coverslip by tweezers. Dry coverslip using a forced air flow for $5 \mathrm{~min}$. Note: The protocol can be paused at this point. The coverslip should be stored at $-20^{\circ} \mathrm{C}$.

3. Immunofluorescence Day 1

NOTE: This stage involves an overnight $(\mathrm{O} / \mathrm{N})$ incubation $(\sim 16 \mathrm{~h})$.

1. Wash the coverslips in $1 \times$ PBS twice.

2. Drop $100 \mu \mathrm{L}$ of antibody dilution buffer (see Table $\mathbf{1}$ for details) onto the coverslip and incubate for $30 \mathrm{~min}$ at RT. NOTE: Solution volume should be adjusted on the basis of the coverslip surface in order to cover the entire coverslip and avoid the risk of overflow.

3. Prepare the antibody mix (Table 1) using a 1:20 dilution of monoclonal primary antibody conjugated with fluorochrome and antibody dilution buffer, as specified in the datasheet provided by the manufacturer.

NOTE: It is strongly advised to use monoclonal antibodies conjugated with thermostable fluorochrome. If a non-thermostable fluorochrome is used, the temperature utilized during the DNA-FISH steps of the protocol may damage the fluorochrome and extinguish the fluorescent emissions. In this protocol, we opted for an EpCAM-FITC antibody (1:20 dilution), which did not show any significant problems with the utilized temperature.

4. Rinse the coverslips twice in $1 \times$ PBS.

5. Place coverslips cell-side up in a humid chamber and drop $100 \mu \mathrm{L}$ of the antibody mix on the coverslip. Note: Solution volume should be adjusted on the basis of the coverslip surface to cover the entire coverslip and lessen the risk of overflow.

6. Incubate $\mathrm{O} / \mathrm{N}(\sim 16 \mathrm{~h})$ in the dark at $4{ }^{\circ} \mathrm{C}$.

4. Immunofluorescence Day 2

1. Block antibody incubation by washing the coverslips in $1 \times$ PBS twice.

NOTE: Store the coverslips immersed in $100 \mu \mathrm{L}$ of $1 \times \mathrm{PBS}$ at $4{ }^{\circ} \mathrm{C}$ in a chamber with constant humid environment in the dark until the FISH assay is performed.

\section{2D DNA-FISH Day 2}

CAUTION: Special attention must be paid to the high temperature of the instruments and the humid chamber.

1. Set up the hybridization oven and dry heat oven $\left(\sim 3 \mathrm{~h}\right.$ before starting the DNA-FISH protocol). Set the hybridization oven at $75^{\circ} \mathrm{C}$, set the dry heat oven at $37^{\circ} \mathrm{C}$ and cool the $0.4 \times$ SSC solution ( $\mathrm{pH}=7.0 \pm 0.1$ ) (for SSC recipe see Table 1) to $4{ }^{\circ} \mathrm{C}$. 
NOTE: $\mathrm{pH}$ status of FISH buffers is critical: $\mathrm{pH}=7.0 \pm 0.1$.

2. Wash the coverslip three times in ice-cold $0.4 \times$ SSC solution.

3. Dry the coverslip under a chemical fume hood for $10 \mathrm{~min}$ in the dark.

4. Vortex for $10 \mathrm{~s}$ and perform a quick spin down (at maximum rate) of the probe from the wall of the probe-tube.

5. Place the coverslip cell-side down onto a drop of $5 \mu \mathrm{L}$ of FISH probe on a slide and seal all the edges of the coverslip with rubber cement.

CAUTION: The next two steps involve high temperatures. Wear protective gloves.

6. Put the slide into a dark humid chamber in the hybridization oven for $8 \mathrm{~min}$ at $75^{\circ} \mathrm{C}$ for complete DNA denaturation.

7. Move the humid chamber into the dry heat oven at $37^{\circ} \mathrm{C} \mathrm{O} / \mathrm{N}$.

\section{2D DNA-FISH Day 3}

1. Set the water bath at $72{ }^{\circ} \mathrm{C}$ and place a slide-staining jar with $0.4 \times \mathrm{SSC}$ buffer into it (Table 1). After 30 min, check the temperature of the $0.4 \times \mathrm{SSC}$ buffer, which must be at $72 \pm 1^{\circ} \mathrm{C}$.

2. Prepare two glass beakers: one with $2 \times \mathrm{SSC}+0.05 \%$ Tween buffer $(\mathrm{pH}=7.0 \pm 0.1)$ (Table 1) and a second one with distilled water.

3. Remove the humid chamber from the oven, carefully remove the rubber cement from the slide and detach the coverslip with tweezers.

4. Wash the coverslip by dipping in $0.4 \times \mathrm{SSC}$ for $2 \mathrm{~min}$ at $72^{\circ} \mathrm{C}$.

5. Wash the coverslip by dipping in $2 \times \mathrm{SSC}+0.05 \%$ Tween buffer for $30 \mathrm{~s}$.

6. Rinse the coverslip in distilled water.

7. Dry the coverslips under a chemical fume hood for $10 \mathrm{~min}$ in the dark.

8. Mount the coverslip in liquid mounting medium with $1.5 \mu \mathrm{g} / \mathrm{mL}$ of $4^{\prime}, 6$-diamidino-2-phenylindole (DAPI) to counterstain total DNA. Place the coverslip cell-side down onto a drop of $5 \mu \mathrm{L}$ of mounting medium on a slide, press the tweezers on the coverslip to get the air out, and seal with nail polish.

Note: Mounting medium volume should be adjusted on the basis of the size of the coverslip surface.

\section{2D microscope observation and analysis}

NOTE: Images can be acquired with different microscope systems. We used a conventional fluorescent microscope endowed with a standard commercial software for image acquisition (Table of Materials).

1. Acquire images using a 12-bit digital camera and 20×/0.50 NA and 40×/0.65 NA objective with appropriate filters for red (excitation: 599 $\mathrm{nm}$, emission: $588 \mathrm{~nm}$ ), green (excitation: 509, emission: 524), and blue (excitation: $367 \mathrm{~nm}$, emission: $452 \mathrm{~nm}$ ) probes.

2. Analyze images using software tool of choice.

NOTE: To evaluate the immunofluorescence staining and the ALK-probe localization, we used ImageJ. Slides can be stored at -20 ${ }^{\circ} \mathrm{C}$ in the dark for a maximum of 3 weeks. For prolonged storage, we would suggest using specific mounting medium for long-term storage.

\section{Immuno-DNA FISH on Wire}

1. Cell line spike-in on wire (3D support)

NOTE: Preliminary set-up involves an accurate selection of adherent cells lines based on EpCAM-positivity. The wire is functionalized with anti-EpCAM antibodies so that only EpCAM-positive cells are stained.

NOTE: Do not touch the functionalized part of the wire to avoid any damage.

NOTE: All steps should be carried out under a laminar flow hood in sterile conditions.

1. Resuspend the entire contents of a T75 flask ( $80 \%$ confluence) in a $5 \mathrm{~mL}$ vial using $4 \mathrm{~mL}$ of complete medium; for a single spike-in, about $2,000,000$ cells are recommended to maximize cells adhesion to the wire.

2. Remove the wire from its glass packaging.

3. Dip the functionalized gold part of the wire into the vial, ensuring that the wire-stopper is a watertight fit for the vial. Seal with laboratory film.

NOTE: The use of $5 \mathrm{~mL}$ tube is recommended to allow for a correct match between the wire-stopper and the vial.

4. Incubate for $30 \mathrm{~min}$ at $\mathrm{RT}$ in a tube rotator (0-120 angle).

5. Rinse the wire three times in $1 \times$ PBS solution using 3 different clean vials.

\section{Fixation and permeabilization}

CAUTION: Acetone is a flammable substance that can irritate the respiratory tract. Only use acetone-resistant plastics or glass containers (no PVC or PVDF).

NOTE: Perform these steps under a chemical fume hood.

1. Air-dry the wire.

2. Fix the cells by dipping the wire in acetone $100 \%$ solution for $10 \mathrm{~min}$ at RT. Use a $5 \mathrm{~mL}$ tube. NOTE: The wire-stopper must not come into contact with the fixative.

3. Air-dry the wire for 5 min at RT.

NOTE: The protocol can be paused here. The wire must be stored at $-20^{\circ} \mathrm{C}$. When packing the wire for long-term storage, place the wire-stopper next to the functionalized tip and carefully insert the wire into the storage glass tube, taking care not to damage the functionalized tip. Close the storage glass and store (vertically or horizontally) at $-20^{\circ} \mathrm{C}$.

3. Immunofluorescence Day 1

NOTE: This stage involves an $\mathrm{O} / \mathrm{N}$ incubation $(\sim 16 \mathrm{~h})$.

1. Wash twice in $1 \times$ PBS solution using $5 \mathrm{~mL}$ tube.

2. Incubate the wire in antibody dilution buffer for $30 \mathrm{~min}$ at RT using $5 \mathrm{~mL}$ tube.

3. Prepare $150 \mu \mathrm{L}$ of antibody mix with a dilution of monoclonal primary antibody conjugated with fluorochrome in antibody dilution buffer, as specified in the datasheet. For example, EpCAM-FITC antibody was used with a 1:20 dilution. 
4. Use a p200 tip to perform incubation, as follows: extract the wire from the wire-stopper and gently insert the wire through the larger hole of the tip. Insert the unfunctionalized end first and slowly pull the wire through the smaller hole until the gold part is just beyond the larger hole.

5. Gently drop $150 \mu \mathrm{L}$ of the antibody mix (for example anti EpCAM_FITC antibody 1:20 diluted) into the tip. To avoid the risk of bubble formation, gently twirl the wire until the functionalized part is completely plunged.

6. Seal up the hole of the tip. Wrapping laboratory film around the hole can help.

7. Incubate vertically $\mathrm{O} / \mathrm{N}(\sim 16 \mathrm{~h})$ in the dark at $4{ }^{\circ} \mathrm{C}$.

\section{Immunofluorescence day 2}

1. Block antibody incubation by washing the wire twice in $1 \times$ PBS.

2. Re-insert the wire in its wire-stopper. NOTE: Store in $1 \mathrm{XPBS}$ at $4{ }^{\circ} \mathrm{C}$ in a $5 \mathrm{~mL}$ vial until the $\mathrm{FISH}$ assay is performed.

\section{3D DNA-FISH Day 2}

CAUTION: Special attention must be paid to the high temperature of the instruments and humid chamber.

1. Set up the hybridization oven and dry heat oven $\left(\sim 3 \mathrm{~h}\right.$ before starting the DNA-FISH protocol). Set the hybridization oven at $75^{\circ} \mathrm{C}$, set the dry heat oven at $37^{\circ} \mathrm{C}$, and cool the $0.4 \times \mathrm{SSC}$ solution $(\mathrm{pH}=7.0 \pm 0.1)$ to $4{ }^{\circ} \mathrm{C}$. NOTE: The pH status of FISH buffers is critical and must be $7.0 \pm 0.1$.

2. Wash the wire 3 times in ice-cold $0.4 \times$ SSC solution. NOTE: Keep the wire in the dark to avoid fluorochrome photobleaching during the following procedures.

3. Dry for $10 \mathrm{~min}$ in the dark under the fume cupboard.

4. Vortex and spin the probe for $5 \mathrm{~s}$.

5. Drop $10 \mu \mathrm{L}$ of the probe into theglass microtubes. Cover with laboratory film.

6. Spin the microtubes as follows: wrap the microtube in a dry absorbent, paper put into a $50-\mathrm{mL}$ tube, and spin briefly.

7. Carefully place the dried wire into the microtube and insert the wire-stopper. Seal with rubber cement. CAUTION: The next two steps involve high temperatures. Wear protective gloves.

8. Put the wire into a dark humid chamber in the hybridization oven for $8 \mathrm{~min}$ at $75^{\circ} \mathrm{C}$ to obtain complete DNA denaturation.

9. Move the humid chamber into a dry heat oven at $37^{\circ} \mathrm{C} O / \mathrm{N}$.

\section{3D DNA-FISH Day 3}

1. Put a slide staining jar with $0.4 \times \mathrm{SSC}$ solution into a water bath and set at $72{ }^{\circ} \mathrm{C}$.

2. Check the $0.4 \times \mathrm{SSC}$ solution temperature until it reaches $72 \pm 1{ }^{\circ} \mathrm{C}$.

3. Prepare two glass beakers, one with $2 \times \mathrm{SSC}+0.05 \%$ Tween $(\mathrm{pH}=7.0 \pm 0.1)$ solution and the second one with distilled water.

4. Remove the humid chamber from the dry heat oven, carefully remove the rubber cement from the wire-stopper using tweezers, and take out the wire.

Note: Carefully pull the uncoated end of the wire through the IN-Stopper, being careful not to damage the functionalized tip.

5. Dip the wire into the $0.4 \times \mathrm{SSC}$ solution for 2 min at $72^{\circ} \mathrm{C}$.

6. Wash the wire in $2 \times \mathrm{SSC}+0.05 \%$ Tween solution for $30 \mathrm{~s}$ at RT.

7. Wash the wire in distilled water at RT.

8. Dry the wire under the fume hood for $10 \mathrm{~min}$ in the dark.

9. Prepare a DAPI stock solution of $1.43 \mu \mathrm{M}$ in $2 \mathrm{~mL}$ of $1 \times$ PBS.

10. Incubate the functionalized tip of the wire with DAPI solution in a $2 \mathrm{~mL}$ vial for $1 \mathrm{~h}$ in the dark at RT.

11. Rinse the wire twice in $1 \times$ PBS and air-dry.

\section{3D microscope observation and analysis}

1. Position the wire in the wire holder. Carefully insert the functionalized tip through the entry point of the special holder, until the tip matches the coupling point. Be careful not to damage the functionalized tip (Figure 1a).

2. Place the special holder on the microscope stage. Adjust the focus of the microscope using a $20 \times$ lens. First coarsely focus on the special support and then adjust finely on cells that appear bright in the DAPI-channel.

3. Only put into focus the cells central to the lens.

Note: Images can be acquired with different microscope systems. In this setting, we use a conventional fluorescent microscope endowed with a standard commercial software for image acquisition.

4. Acquire images using a 12-bit digital camera and 20×/0.50 NA and 40×/0.65 NA objective with appropriate filters for red (excitation: 599 $\mathrm{nm}$, emission: $588 \mathrm{~nm}$ ), green (excitation: 509, emission: 524), and blue (excitation: $367 \mathrm{~nm}$, emission: $452 \mathrm{~nm}$ ) probes. Note: Images can be visualized using different tools and software. We use ImageJ to evaluate immunofluorescence staining and ALKprobe localization.

Note: The protocol can be paused here. The wire must be stored at $-20^{\circ} \mathrm{C}$. When packing the wire for long-term storage, place the wire-stopper next to the functionalized tip and carefully insert the wire into the storage glass tube, taking care not to damage the functionalized tip. Close the storage glass and store (vertically or horizontally) at $-20^{\circ} \mathrm{C}$.

\section{Representative Results}

Using the procedure described above it is possible to perform an Immuno-DNA FISH assay on CTCs (or other equivalent cells) enriched by the functionalized wire. Before setting up this protocol, the compatibility of the two techniques was determined (immuno-fluorescence with FISH) on standard 2D supports. Two different NSCLC cell lines expressing EpCAM (required to adhere to the wire coupled with antibodies against EpCAM) were selected. They have a different ALK status, which is useful to test different starting conditions. The first, NCl-H1975, have wild type (WT) ALK genes, while the second, NCl-H3122, is characterized by ALK translocations. 
An ALK gene break-apart detection system for the FISH assay was used. The system consists of two probes, one (orange) hybridizing to the proximal region within ALK on 2p23 and one (green) hybridizing distal to ALK. On 2D supports, Immuno-DNA FISH provided well-defined signals for both antibody and probe (Figure 2). In particular, both cell lines showed well-defined EpCAM membrane localization. Furthermore, probe signals appeared bright and sharp: NCl-H1975 cells showed overlapping orange and green probes, confirming the wildtype status of ALK gene (Figure 2a, b). Conversely, NCl-H3122 cells showed overlapping signals and single green dots, reflecting a deletion of ALK gene (Figure 2c, d). When the Immuno-DNA FISH assay was performed on the 3D support functionalized wire, antibody and probe signals were generally less defined than on the 2D support. EpCAM staining was visible. ALK probe signals were less defined but still reflected the expected ALK status (Figure 3). Results showed that immunofluorescence staining did not interfere with DNA FISH signals. The probes hybridized specifically with their targets. NCl-H3122 cell line showed an aberrant ALK gene status (Figure 3b), in contrast to NCl-H1975, with a wild type ALK gene (Figure 3a).

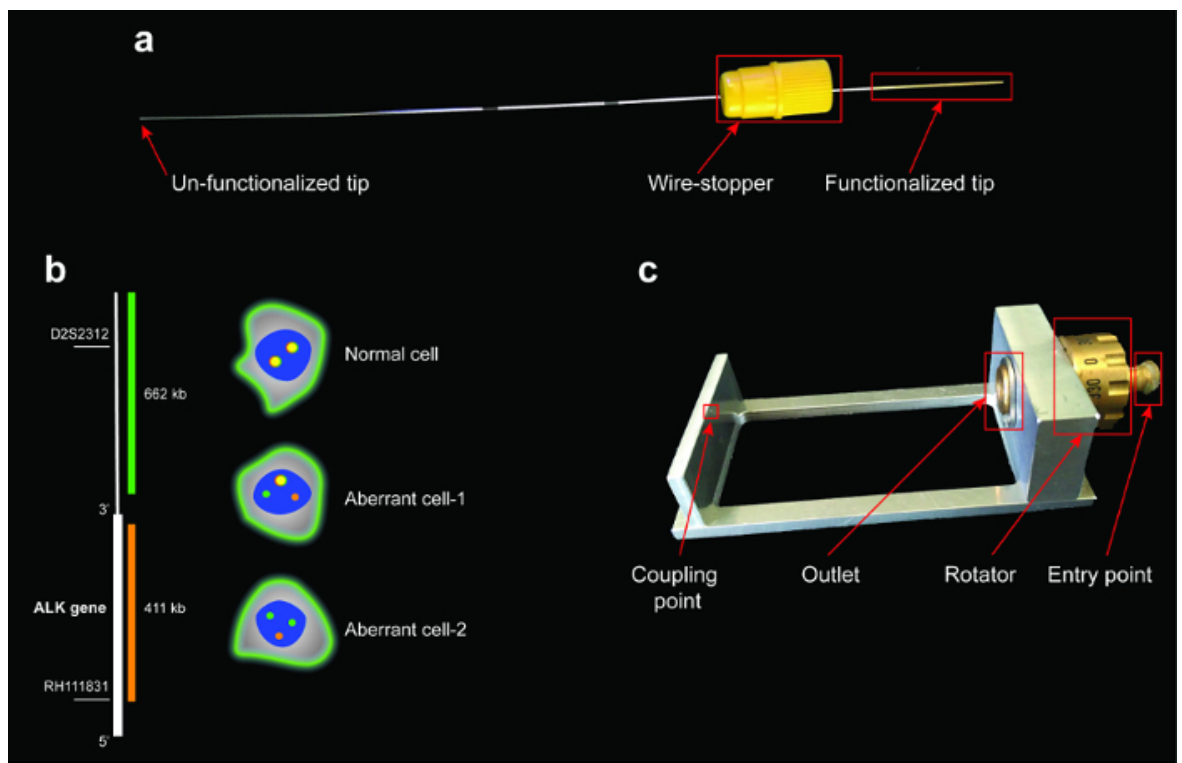

Figure 1: Functionalized wire, schematic arrangement of ALK break-apart probes, scheme of expected patterns of ALK rearrangement, and special holder. (a) Red boxes highlight the three main parts of the wire: functionalized tip, wire-stopper, and un-functionalized tip. The functionalized tip is the most delicate part of the wire and must not be touched during handling to avoid cell detachment or damage. (b) The green and red probes each respectively bind to sequences upstream and downstream of the loci of ALK gene (on the left). On the right, exemplificative patterns of ALK arrangements are shown. Red and green co-localization signals on normal cells; separated green and red signals indicate an ALK gene chromosome break (translocation of ALK gene) and one green-orange colocalization signal (aberrant cell-1). One red signal and two green signals indicate the loss of one red signal, suggesting a chromosomal translocation and a deletion (aberrant cell-2). (c) Wire holder; red boxes highlight areas where care is needed when handling the wire during microscopy analysis. The wire can undergo a $360^{\circ}$ analysis by turning the rotator. Please click here to view a larger version of this figure. 
a

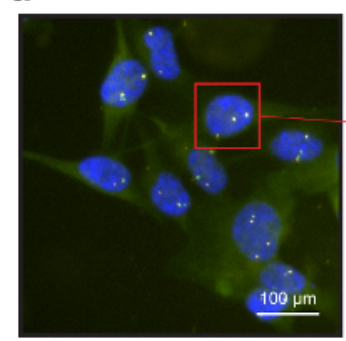

C

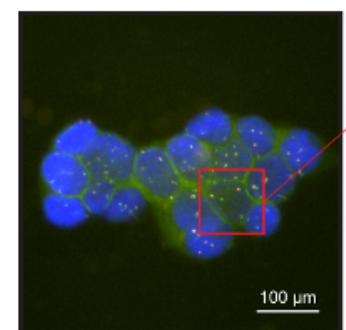

b
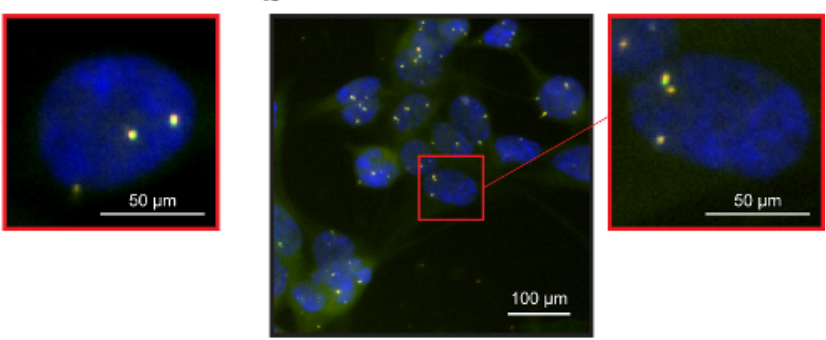

d
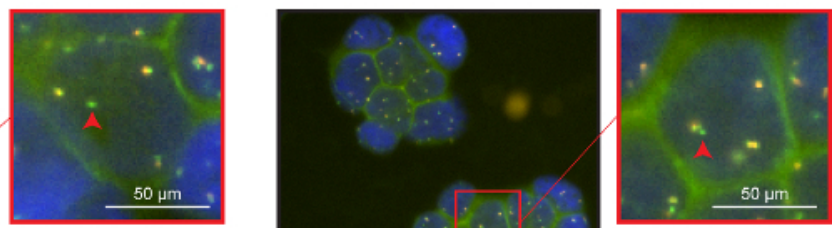

Figure 2: Immuno-DNA FISH assay on 2D support (coverslip). (a, b) NCI-H1975 cells weakly positive for EpCAM. EpCAM FITC signals were appreciable. The orange and green probes of the ALK break-apart overlapped, confirming the WT status of ALK gene in NCIH1975 cell line. Cells displaying more than two paired signals were present due to their aneuploidy. (c, d) In the high EpCAM-expressing NCIH3122 cell line, immunofluorescence signals were bright, which was accentuated in cell-cell junctions. FISH analyses confirmed deletions of the ALK gene, typical of this cell line. Red arrows indicate single green probes (without corresponding orange probes), reflecting ALK gene deletion. Please click here to view a larger version of this figure.

a
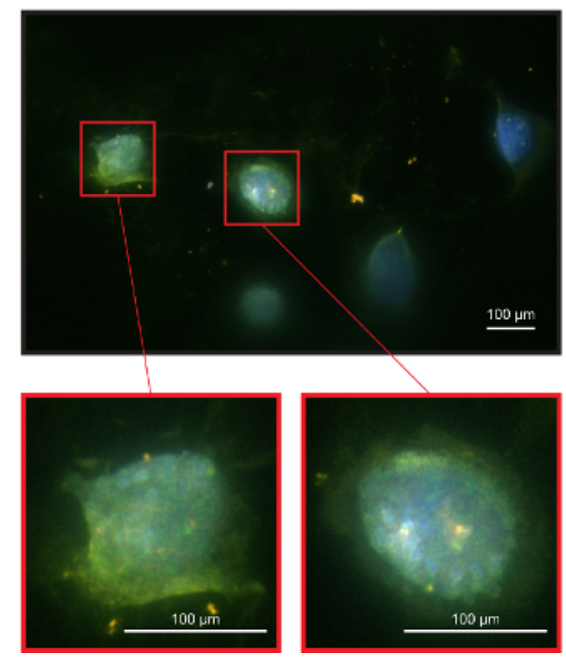

b
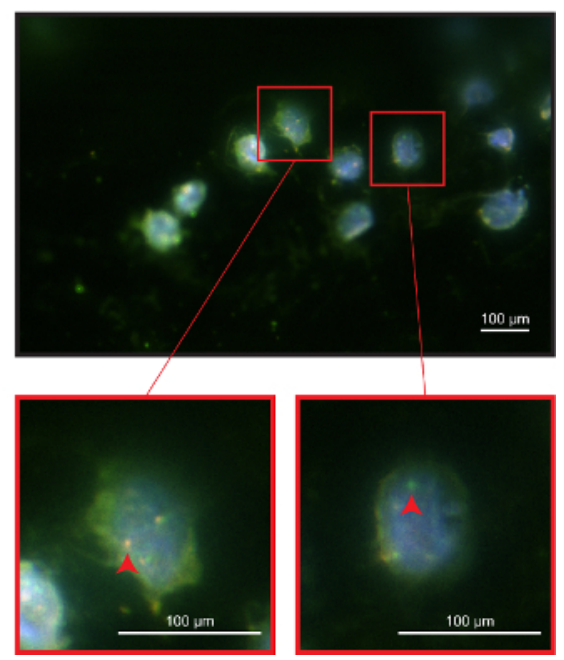

Figure 3: Immuno-DNA FISH assay using the functionalized wire as 3D support. (a) Representative image of NCI-H1975 cells on the wire. Although the 3D shape of the cells on the wire make difficult to acquire fully in-focus images, EpCAM signal is well visible in all the cells. (b) Representative image of $\mathrm{NCl}-\mathrm{H} 3122$ cells on the wire. ALK probes showed gene deletion (red arrows), as previously seen on the 2D support. The visible background signals were most likely due to the presence of the polymer layer. However, it did not significantly affect cell identification or fluorescence analysis. Please click here to view a larger version of this figure. 


\begin{tabular}{|c|c|c|c|}
\hline Buffer & Composition & note & Stocks \\
\hline Cell complete culture medium & $\begin{array}{l}\text { RPMI } 1640+2 \mathrm{mM} \text { Glutamine + } \\
5-10 \% \text { Foetal Bovine Serum (FBS). }\end{array}$ & & $\begin{array}{l}\text { RPMI: } 4{ }^{\circ} \mathrm{C} \text {; Glutamine, FBS:-20 } \\
{ }^{\circ} \mathrm{C}\end{array}$ \\
\hline Antibody Diluition Buffer & $\begin{array}{l}1 \% \text { BSA, } 0.3 \% \text { Triton } \mathrm{X}-100 \text { in } 1 \mathrm{x} \\
\text { PBS }\end{array}$ & & RT. Seal with laboratory film. \\
\hline 20x SSC Solution & $\begin{array}{l}3 \mathrm{M} \text { sodium chloride, } 300 \mathrm{mM} \\
\text { trisodium citrate dissolved in } \\
\mathrm{ddH}_{2} \mathrm{O}\end{array}$ & $\begin{array}{l}\text { Filter solution and } \mathrm{pH}=7.0+/-0.1 \\
\text { with } \mathrm{HCl}\end{array}$ & RT. Seal with laboratory film. \\
\hline 0.4x SSC Solution & $\begin{array}{l}\text { Dilute stock 20x SSC in distilled } \\
\mathrm{H}_{2} \mathrm{O}\end{array}$ & $\begin{array}{l}\text { Filter solution and } \mathrm{pH}=7.0+/-0.1 \\
\text { with } \mathrm{HCl}\end{array}$ & RT. Seal with laboratory film. \\
\hline $\begin{array}{l}2 x \text { SSC }+0.05 \% \text { Tween } 20 \\
\text { Solution }\end{array}$ & $\begin{array}{l}\text { Dilute stock 20x SSC in distilled } \\
\mathrm{H}_{2} \mathrm{O}+0.05 \% \text { Tween } 20\end{array}$ & $\begin{array}{l}\text { Filter solution and } \mathrm{pH}=7.0+/-0.1 \\
\text { with } \mathrm{HCl}\end{array}$ & RT. Seal with laboratory film. \\
\hline DAPI Solution $30 \mathrm{nM}$ & Dilute stock $1.43 \mu \mathrm{M}$ in $1 \times$ PBS & & $\begin{array}{l}-20^{\circ} \mathrm{C} \text { in dark condition ready to } \\
\text { use aliquote }\end{array}$ \\
\hline
\end{tabular}

Table 1: Solutions recipes.

\section{Discussion}

In this paper, for the first time, a method combining immunofluorescence staining and DNA FISH, for use with the functionalized wire was proposed. The method was called Immuno-DNA FISH. This technique was developed to permit the simultaneous identification of putative CTCs on a 3D wire on the basis of phenotypical parameters, such as positivity to EpCAM (event 1), and to facilitate the detection of molecular alterations, such as ALK gene status (event 2). The simultaneous identification of the two events allows the detection of their co-localization. Hence, this approach can be tailored to identify and characterize CTCs retrieved from the blood of cancer patients. The potential effects of haemo-components and leukocytes on the staining procedure do not usually interfere with the procedure. In particular, data reported in literature indicated that haemo-components and leukocytes do not influence the immunofluorescence staining of the cells attached to the wire, the critical step to identify actual CTCs ${ }^{1,15}$.

The fluorescence brightness of Immuno-DNA FISH is slightly less marked than that of a traditional immunophototyping assay and is the result of the high temperature needed for the FISH assay. However, immunofluorescence staining is still appreciable. For example, a faint signal is still detectable in the low EpCAM-expressing cell line, $\mathrm{NCIH1975.} \mathrm{The} \mathrm{high} \mathrm{temperature} \mathrm{required} \mathrm{for} \mathrm{the} \mathrm{FISH} \mathrm{assay} \mathrm{is} \mathrm{the} \mathrm{main} \mathrm{limiting} \mathrm{factor}$ in choosing the right fluorochrome linked to the antibody. In this protocol, antibodies must be linked to a thermostable fluorochrome in order to tolerate the DNA denaturation temperature. For example, phycoerythrin, a thermosensitive fluorochrome, is not recommended in this setting because of fluorochrome degradation caused by high temperature. Fluorescein isothiocyanate is a good choice and often common fluorochrome employed on FISH probes. The Immuno-DNA FISH autofluorescence signal is very poor on standard 2D supports. On the wire support, the polymer layer may induce a slight autofluorescence signal, especially on the red channel. Unlike the 2D background, an aspecific background signal is discernible on the wire but does not significantly affect nuclei identification or cell characterization.

Microscope evaluation of the wire is much more fatiguing than on a 2D support due to the limits of an optical microscope in reading the surface of a cylindrical-shaped 3D structure. However, this difficulty can be overcome by rotating the wire holder and acquiring the images that are mainly localized along the midline of the wire. The wire holder permits a $360^{\circ}$ rotation of the wire. Once focused on the nuclei, changing fluorescence channels does not necessarily keep the focus on the target area. For this reason, it is essential to maintain the focus on the inner-cell target area.

This technique can be tailored to detect and characterize cells on different kinds of 3D supports. It may also be possible to use different antibodies and FISH probes. When choosing to use different antibodies, fluorochrome thermostability and the expression level of the target antigen on the cell membrane are important factors to consider. Intra-cytoplasmatic antigens can also be stained. When using different FISH probes, it is important to check the datasheet specifications for the denaturation procedure and to prepare cells for the FISH assay accordingly.

\section{Disclosures}

The authors declare that they have no competing financial interests.

\section{References}

1. Saucedo-Zeni, N. et al. A novel method for the in vivo isolation of circulating tumor cells from peripheral blood of cancer patients using a functionalized and structured medical wire. Int. J. Oncol. 41 (4), 1241-50 (2012).

2. $\mathrm{Xu}, \mathrm{W}$. et al. Comparison of three different methods for the detection of circulating tumor cells in mice with lung metastasis. Oncol. Rep. , 1-8 (2017).

3. Chen, S. et al. Catch and Release: rare cell analysis from a functionalised medical wire. Sci. Rep. 7 (February), 43424 (2017).

4. Masuda, T., Hayashi, N., Iguchi, T., Ito, S., Eguchi, H., \& Mimori, K. Clinical and biological significance of circulating tumor cells in cancer. Mol. Oncol. 10 (3), 408-417 (2016).

5. Toss, A., Mu, Z., Fernandez, S., \& Cristofanilli, M. CTC enumeration and characterization: moving toward personalized medicine. Ann. Transl. Med. 2 (11), 108 (2014). 
6. Wang, J., Huang, J., Wang, K., Xu, J., Huang, J., \& Zhang, T. Prognostic significance of circulating tumor cells in non-small-cell lung cancer patients: a meta-analysis. PLoS One. 8 (11), e78070 (2013).

7. Maemondo, M. et al. Gefitinib or Chemotherapy for Non?Small-Cell Lung Cancer with Mutated EGFR. N. Engl. J. Med. 362 (25), 2380-2388 (2010).

8. Shaw, A. T. et al. Crizotinib versus Chemotherapy in Advanced ALK -Positive Lung Cancer. N. Engl. J. Med. 368 (25), 2385-2394 (2013).

9. Borghaei, H. et al. Nivolumab versus Docetaxel in Advanced Nonsquamous Non-Small-Cell Lung Cancer. N. Engl. J. Med. 373 (17), 1627-39 (2015).

10. Costa, D. B. et al. Clinical Experience With Crizotinib in Patients With Advanced ALK -Rearranged Non-Small-Cell Lung Cancer and Brain Metastases. J. Clin. Oncol. 33 (17), 1881-1888 (2015).

11. Fischer, J. C. et al. Diagnostic leukapheresis enables reliable detection of circulating tumor cells of nonmetastatic cancer patients. Proc. Natl. Acad. Sci. U. S. A. 110 (41), 16580-5 (2013).

12. Coumans, F. a W., Ligthart, S. T., Uhr, J. W., \& Terstappen, L. W. M. M. Challenges in the enumeration and phenotyping of CTC. Clin. Cancer Res. 18 (20), 5711-5718 (2012).

13. Allard, W. J., \& Terstappen, L. W. M. M. CCR 20th Anniversary Commentary: Paving the Way for Circulating Tumor Cells. Clin. Cancer Res. 21 (13), 2883-2885 (2015).

14. Theil, G. et al. The use of a new CellCollector to isolate circulating tumor cells from the blood of patients with different stages of prostate cancer and clinical outcomes - A proof-of-concept study. PLoS One. 11 (8), 1-14 (2016).

15. Gorges, T. M. et al. Enumeration and Molecular Characterization of Tumor Cells in Lung Cancer Patients Using a Novel In Vivo Device for Capturing Circulating Tumor Cells. Clin. Cancer Res. 22 (9), 2197-206 (2016). 